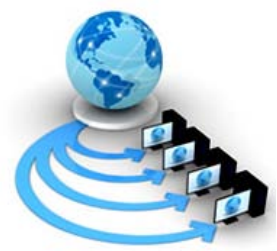

Volume 9, No. 2, March-April 2018

REVIEW ARTICLE

Available Online at www.ijarcs.info

\title{
LOAD BALANCING TECHNIQUES IN CLOUD COMPUTING
}

\author{
Bharti \\ CSE Department \\ Dcrust, Murthal \\ Sonipat, India
}

\author{
Dr. Suman Sangwan \\ CSE Department \\ Dcrust, Murthal \\ Sonipat, India
}

\begin{abstract}
In today's era, distributed computing is rising in the field of data processing. It gives a broad measure for the services to be processed for clients through the web. Everyone's data is on cloud. There resides many problems when we process data on cloud like as security, privacy etc. And load balancing is one of the problem in cloud computing. There are many requests generating on a single virtual machine and these requests are to be processed on various machines. This is controlled by load balancer. Load balancing is the technique used for assigning different- different tasks on different- different virtual machines by using various algorithms. Load balancing plays a vital role in the era of cloud computing which is assumed to circulate on various machines. This paper presents the study of various load balancing techniques.
\end{abstract}

Keywords: Load balancing, Cloud computing, Virtual machines.

\section{INTRODUCTION}

Cloud computing is a paradigm used for storage capacity, computation and services among massive users. In essence, cloud computing [1] overlaps many existing concepts such as grid, distributed and utility computing. Big cooperates like Google, Amazon and IBM offering services evolved these concepts and are focusing on Cloud Computing. If cloud computing steps into our daily life then our information such as our email, spreadsheet, word processing which we locally store on our desktop can be stored remotely on various virtual machines residing on cloud. Then we can access these services at any time from any terminal. Due to these characteristics cloud computing is becoming more attractive to people. The cloud in cloud computing can be defined as the set of hardware, networks, storage, services and interfaces that combine to deliver aspects of computing as services [2].

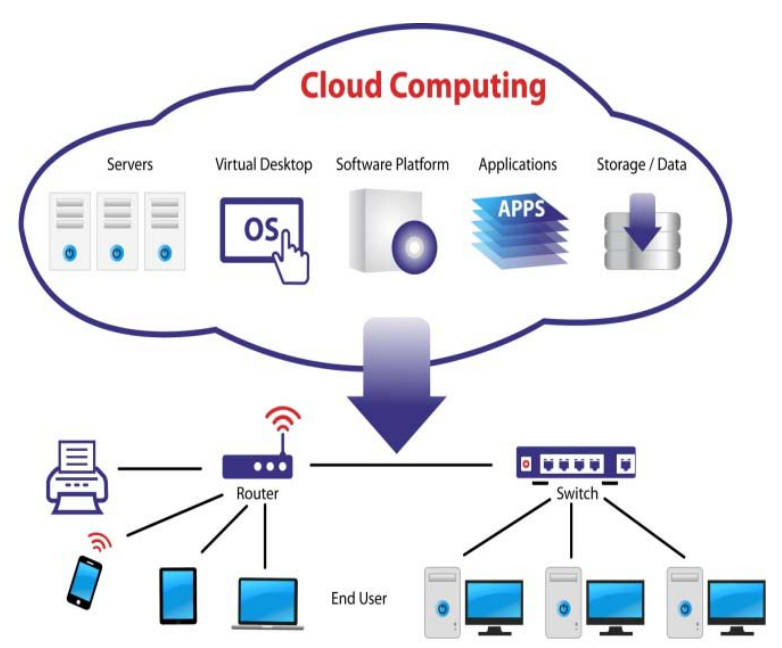

Figure 1.1 General architectuure of Cloud Computing [3]

Figure 1.1 shows the typical architecture of cloud computing. The flexibility characteristics of cloud computing attracts individuals and business to move on the cloud. Load balancing is the process of reassigning various tasks to the different-different individuals to improve the job response time and to improve the process of balancing the load in an efficient manner. The load which we would consider for load balancer can be any type of load such as network load, CPU load or can be memory load.

\section{LITERATURE REVIEW}

Rakpong Kaewpuang, et al. (2009) [4] proposed a logistic application known as "Pickup and Delivery Problem with Time Window". The results show the high execution speed for the target applications.

Yushuang Dong, et al. (2011) [5] proposed a load balancing ant colony optimization algorithm. The algorithm balances the entire system load and minimize the make span of the given tasks set. The size of tasks may or may not be equal. LBACO works in all conditions.

Kumar Nishant, Parteek Sharma, et al. (2012) [6] proposed ant colony optimization for balancing the node on various nodes. In this approach ants continuously update a single result set instead of updating their own result set.

Ekta Gupta, et al. (2014) [7] proposed the technique for load balancing which is based on ant colony optimization. It detects the servers that are overloaded and under loaded and performs the operations for balancing the load between the identified servers of data centers.

De-Shan Wu, et al. (2015) [8] proposed a distributed virtual migration strategy which is based on ant colony optimization. In the strategy local migration agent would autonomously monitors the resource utilization and considering this monitor it launches the migration. While monitoring, it takes both current and previous state and then makes the decision based on the states. 
Safi Abbas Mahmoud, et al. (2015) [9] proposed an ant lion optimizer (ALO) technique. This technique overcomes the problem of network overhead and local optima problems. Due to this the performance of task assigning process and processing time of these tasks increases.

S. Sangwan, et al. (2015) [10] aims at a critical review and comparison of the existing techniques for load balancing. The paper surveyed about various static and dynamic technology of load balancing. The paper focuses at the need of load balancing in cloud computing and describe the various reasons to do so.

Anuradha, et al. (2015) [11] proposed a hybrid approach of encryption techniques. The main benefit of the hybrid scheme is to give more security in the cloud. The hybrid algorithm is based on the password and security key. In this case the client is free from the fear that the administrator knows the password. The password and security key are saved in database.

Sham Singh Rajput, et al. (2016) [12] proposed improved load balanced min-min (ILBMM) algorithm using genetic algorithm (GA). It minimizes the make span and increases the utilization of resources effectively.

Dr. Priyanka Tripathi et al. (2016) [13] shows a comparison to evaluate various existing load balancing techniques. By this comparison, performance can be improved. The various load balancing techniques are analyzed here.

Dr. Uma KUmari et al. (2016) [14] presents cloud computing architecture, virtualization, load balancing issues and various load balancing algorithms. Load balancing is a technique which provides methods to maximize output, use of resources in efficient manner and performance of the system.

Aashish Gupta et al. (2017) [15] presents a meta- heuristic approach of ACO algorithm to solve the task scheduling problem in cloud environment. Comparative analysis shows that proposed LB- ACO provides better results.

\section{Comparative analysis}

\begin{tabular}{|c|c|c|c|c|}
\hline Year & Algorithm & Description & Pros & Cons \\
\hline 2008 & $\begin{array}{l}\text { Active } \\
\text { Clustering }\end{array}$ & $\begin{array}{l}\text { Self aggregation algorithm that } \\
\text { works on the principle of grouping } \\
\text { similar nodes. }\end{array}$ & $\begin{array}{l}\text { Balances nodes in an } \\
\text { efficient manner. }\end{array}$ & $\begin{array}{l}\text { When there are nodes of } \\
\text { different types, works } \\
\text { poorly. }\end{array}$ \\
\hline 2011 & $\begin{array}{l}\text { Dynamic } \\
\text { Round Robin }\end{array}$ & $\begin{array}{l}\text { Based on Retiring states of VM and } \\
\text { migration of VM. }\end{array}$ & $\begin{array}{l}\text { The power consumption } \\
\text { cost was reduced. }\end{array}$ & $\begin{array}{l}\text { Doesn't work for large data } \\
\text { centers. }\end{array}$ \\
\hline 2011 & $\begin{array}{l}\text { Join-Idle- } \\
\text { Queue. }\end{array}$ & $\begin{array}{l}\text { Balance load across dispatchers and } \\
\text { then assign jobs to processors. }\end{array}$ & Reduce system load. & More power consumption. \\
\hline 2011 & Randomized. & It randomly assigns jobs to VM. & $\begin{array}{l}\text { It is very simple } \\
\text { algorithm. }\end{array}$ & $\begin{array}{l}\text { Current load is not } \\
\text { considered. }\end{array}$ \\
\hline 2012 & $\begin{array}{l}\text { AMLB } \\
\text { algorithm. }\end{array}$ & $\begin{array}{l}\text { Request is allocated to least loaded } \\
\text { VM. }\end{array}$ & $\begin{array}{l}\text { Consider availability and } \\
\text { also load of VM. }\end{array}$ & $\begin{array}{l}\text { Processing power of VM is } \\
\text { not considered. }\end{array}$ \\
\hline 2012 & $\begin{array}{l}\text { Honey bee } \\
\text { foraging. }\end{array}$ & $\begin{array}{l}\begin{array}{l}\text { Decentralized honey based load } \\
\text { balancing technique. }\end{array} \\
\end{array}$ & \begin{tabular}{ll|}
$\begin{array}{l}\text { Balances } \\
\text { efficiently. }\end{array}$ & load \\
\end{tabular} & $\begin{array}{l}\text { Migration communication } \\
\text { delay was not considered. }\end{array}$ \\
\hline 2013 & LBIMM & $\begin{array}{l}\text { If calculated completion time is less } \\
\text { than make span of min-min then it is } \\
\text { reassigned to resource. }\end{array}$ & $\begin{array}{l}\text { Reduces the overall } \\
\text { completion time. }\end{array}$ & $\begin{array}{l}\text { Doesn't consider the } \\
\text { priority of jobs. }\end{array}$ \\
\hline 2014 & $\begin{array}{l}\text { Max-Min } \\
\text { algorithm. }\end{array}$ & $\begin{array}{l}\text { Similar to Min-Min except that large } \\
\text { jobs will be executed first. }\end{array}$ & Reduces the make span. & $\begin{array}{l}\text { Smaller jobs have to wait } \\
\text { for a long time. }\end{array}$ \\
\hline 2015 & $\begin{array}{l}\text { Memetic } \\
\text { algorithm }\end{array}$ & $\begin{array}{l}\text { Local search algorithm which are } \\
\text { invoked according to search process. }\end{array}$ & $\begin{array}{l}\text { Local search method is } \\
\text { good for solving these } \\
\text { problems. }\end{array}$ & $\begin{array}{l}\text { Such algorithms are } \mathrm{CPU} \\
\text { insensitive. }\end{array}$ \\
\hline 2016 & $\begin{array}{l}\text { Weighted } \\
\text { round robin. }\end{array}$ & $\begin{array}{l}\text { Weight is assigned to each VM based } \\
\text { on its processing capacity. }\end{array}$ & $\begin{array}{l}\text { Better } \\
\text { utilization. }\end{array}$ & $\begin{array}{l}\text { Processing time of each } \\
\text { request is not considered. }\end{array}$ \\
\hline
\end{tabular}

\section{CONCLUSION}

Load balancing is a big challenge in cloud computing. It is difficult to maintain to make idle services or to fulfill all the required demands. So there is distributed environment always in need. The components are present throughout the wide area network. Jobs cannot be assigned to the appropriate servers and clients individually efficiently. Load balancing algorithms are classified into two categories as static and dynamic algorithms. Static algorithms are suitable for homogeneous and stable environments. They produce very good results in these environments. But they are not flexible and do not match up with dynamic algorithms in execution prospective. Dynamic algorithms are more flexible and are better prior to as well as during the run time of tasks. Load balancing is the process of improving the performance of system through the redistribution of load on various VMs. In future work, ant colony optimization will utilize to tackle all the problems in cloud computing. ACO works distributed and in parallel. Hence they distribute load in an efficient manner on cloud. 


\section{REFRENCES}

[1] Yubin Yang; Hui Lin; Jixi Jiang,"Cloud analysis bu modeling the integration of heterogeneous satellite data and imaging”, IEEE, Systems,Man and Cybermetics,Part A: Systems and Humans,IEEE Transcations on, 2006.

[2] Tao Wu, Kum Qin,” Inducing Uncertain Decision Tree via Cloud Model",IEEE Semantics, Knowledge and Grid,2009.SKG 2009. Fifth International Conference on 2009.

[3] Source:https://www.google.co.in/search?hl=en\&tbm=isch \&source=hp\&biw=1242\&bih=602\&ei=zZ0NWu6cA0Tav gSEvou4CA7q=cloud+computing\&0q=cloud+com\&gs_1 =img.3.0110.439.5385.0.7068.10.10.0.0.0.0.375.1437.0j5j $0 j 2.7 .0 \ldots 0 \ldots 1.1 .64$.img..3.7.1436.0...0.IWdmjiKZNk\#imgrc=-Kw39aZyF6F_iM:

[4] Rakpong Kaewpuang,Putching Uthayopas and Ganid Srimool, Juta Pichitlamkhen”, Building a Service Oriented Cloud Computing Infrastructure using Microsoft CCR/DSS System”, Fourth International Conference on Computer Sciences and Convergence Information Technology, 2009.

[5] Kun Li,Gaochao Xu,Guangyu Zhao,Yushuang Dong,Dan Wang,"Cloud Task scheduling based on Load Balancing Ant Colony Optimization”, Sixth Annual ChinaGrid Conference, IEEE Conference, 2011.

[6] Kumar Nishant,Pratik Sharma,Vishal Krishna, Chhavi Gupta and Kunwar Pratap Singh Nitin and Ravi Rastogi,"Load Balancing of Nodes in Cloud Using Ant Colony Optimization", $14^{\text {th }}$ International Conference on Modelling and Simulation, 2012.

[7] Ekta Gupta, Vidya Deshpande,"A Technique Based on Ant Colony Optimization for Load Balancing in Cloud Data Center”, $13^{\text {th }}$ International Conference on Information Technology, 2014.
[8] Wei-Tao Wen, Chang-Dong Wang, De-Shen Wu and Ying-Yan Xie,”An Aco Based Scheduling Strategu on Load Balancing in Cloud Computing Environment”, Nintg International Conference on Frontier of Computer Science and Technology, 2015.

[9] Aya A. Salah Farrg, Safi Abbas Mahmoud, EI Sayed M. EI-Horbtay,"Intelligent Cloud Algorithms for Load Balancing problems: A Survey" IEEE Seventh International Conference on Intelligent Computing and Information Systems(ICiCIS’J5), 2015.

[10] Shikha Gupta, Suman Sangwan,’Load Balancing in Cloud Cimputing: A Review " International Journal of Science, Engineering and Technology Research (IJSTER), Volume 4, Issue 6, 2015.

[11] Anuradha, Sangwan Suman ,’International Journal of Advance Search, Ideas and Innovatives in Technology.", Volume 2, Issue 5, 2016.

[12] Shyam Singh Rajput, Virendera Singh Kushwah,” A Genetic based Improved Load Balancesd Min-Min Task Scheduling Algorithm for Load Balancing in Cloud Computing”, $8^{\text {th }}$ International Conference on Computational Intelligence and Communication Networls, 2016.

[13] Palak Shrivastava, Sudheer Kumar Arya , Dr. Priyanka Tripathi,” Various Issues \& Challenges of Load Balancing Over Cloud: A Survey", International Journal Of Engineering And Computer Science ISSN: 2319-7242 Volume 5, Issues 8, Page No. 17517-17524, Aug 2016.

[14] Dr. Uma Kumari, Ms. Shalini Joshi,” Load Balancing in Cloud Computing: Challenges \& Issues”, 978-1-50905256-1/16/\$31.00 с 2 IEEE, 2016.

[15] Ashish Gupta, Ritu Garg,” Load Balancing Based Task Scheduling with ACO in Cloud Computing", International Conference on Computer and Applications (ICCA), 2017. 